\title{
Using AIN-Coated Heat Sink to Improve the Heat Dissipation of LED Packages
}

\author{
Ming-Der Jean ${ }^{1,}{ }^{*}$, Ji-Bin Jiang ${ }^{1}$, Ming-San $\mathrm{Xu}{ }^{1}$, and Jia-Yi Chien ${ }^{2}$ \\ ${ }^{1}$ School of Mechanical and Automotive Engineering/FuJian University of Technology, Fuzhou 350118, China. \\ ${ }^{2}$ School of Nursing/National Taipei University of Nursing and Health Science, Taipei 11219, Taiwan.
}

\begin{abstract}
This study optimizes aluminum nitride (AlN) ceramics, in order to enhance the thermal performance of light-emitting diode (LED) packages. AlN coatings are grown on copper/ aluminum substrates as a heat interface material, using an electrostatic spraying process. The effect of the deposition parameters on the coatings is determined. The thermal performance of $\mathrm{AlN}$ coated $\mathrm{Cu} / \mathrm{Al}$ substrates is evaluated in terms of the heat dissipated and compared by measuring the LED case temperature. The structure and properties of the coating are also examined a scanning electron microscopy (SEM). In sum, the thermal performance of the LED is increased and good heat resistance characteristics are obtained. The results show that using AlN ceramic coating on a copper/aluminum substrate increases the thermal performance.
\end{abstract}

\section{Introduction}

Light emitting diodes (LEDs) represent the new generation light sources and have attracted considerable attention because they are used in solid lighting devices. LEDs are more efficient than most traditional light sources because they have a long lifetime, high reliability, high efficiency and are environmentally friendly, so they are widely used in many applications. Current LEDs only have an efficiency of about $20 \%$ and around $80 \%$ of the energy is used to generate heat at the junction for the LED modules so most of the electrical power is converted to heat rather than light [1-3]. Insufficient heat dissipation in LEDs reduces light emission efficiency and shortens a LED lamp's lifetime. Therefore, thermal management, which ensures the rapid dissipation of the heat that is generated in the LED chip through a heat sink, is crucial for LED modules. Various solutions have been proposed [4-7].

Fire Retardant 4, which uses a conventional metal PCB and silicon submount was commonly used in the past as the material for electrical circuit boards for LEDs. It is currently used structurally and has an isolation layer with very low thermal conductivity. This structure gives the junction between the LED chip and metal PCB, which is formed by soldering, a large thermal resistance, so heat that is generated by the chip is rapidly transferred to the heat sink, but this heat transfer is limited by the die attachments and thermal conductivity grease, each of which have a high thermal resistance. Several recent studies have tried to improve the thermal conductivity of the base substrates by using alumina ceramic, AlN ceramic, silicon and Al metal PCB [8-11]. Several studies have reported noticeable improvements in the performance of LED' $s$ when ceramics with high thermal-conductivity are used to coat substrates [12-15]. However, cost reduction is a continuous requirement for LED packages and LED manufacturers must reduce the cost of producing LED modules. Aluminum nitride (AIN) coatings are commonly used for heat dissipation in LEDs packaging devices because of their high optical transparency and their thermal and chemical stability [16-22]. Very few studies have reported the use of electrostatically sprayed AlN coatings as a thermal interface material. To meet the demands of the electronics industry, highly conductive materials with reasonable production costs and the optimization of AlN coatings are necessary.

In this study, AlN films are optimally deposited on $\mathrm{Al} / \mathrm{Cu}$ substrates by electrostatic spraying. The effect of the parameters for the AlN coating process is then determined. The morphology, the microstructure and the thermal performance of the LED packages are also determined. An optimized AlN coating is identified that compares very satisfactorily with the experimental results.

\section{EXPERIMENTAL DETAILS}

\subsection{Aluminum nitride coated heat sink}

AlN coatings were deposited on $\mathrm{Cu} / \mathrm{Al}$ substrates $(55 \mathrm{~mm}$ in diameter and $2 / 3 / 5 \mathrm{~mm}$ in thickness) using an

* Corresponding author: mdjeam@foxmail.com 
electrostatic spraying system. The fabricated LED packaging system is composed of the LED module, an aluminum substrate, AIN coatings and a heat sink that uses both $\mathrm{Al}$ and $\mathrm{Cu}$ substrates, a 1.2W LED light source with a metal core printed parallel circuit board and a starter. AlN is a unique ceramic material that has outstanding properties, such as high thermal conductivity $\left(280 \mathrm{Wm}^{-1} \mathrm{~K}^{-1}\right)$, low electrical resistivity and chemical stability. In this study, AlN coatings are studied to assess their effectiveness for thermal management. During the assembly process, the aluminum substrate was bonded with the starter and the thermal interface material was attached to the heat sink. The interfaces were coated with an AlN and these were optimized to minimize the contact thermal resistance. In order to understand the thermal performance of the $\mathrm{AlN}$ coated $\mathrm{Cu} / \mathrm{Al}$ substrates in terms of the heat dissipated, a 1.2-watt LED light source was used. The junction temperature $(\mathrm{Tj})$ of the LED chips that were fixed on the AlN coated $\mathrm{Cu} / \mathrm{Al}$ substrates was evaluated by measuring the case temperature because the junction temperature is difficult to measure directly. In this study, the junction temperature is the main quality characteristic that is used to evaluate the LED package. The case temperature at various locations was directly measured using a thermographic camera (IRI-4010) that offers true 3D thermal mapping software and allows precise visualization, measurement and comparison of the thermal maps. The illumination device comprised four $0.3 \mathrm{~W}$ LEDs that used InGaN-based chips and a base substrate with AIN ceramics, assembled in a LED package. The deposited surface morphology of the AIN coatings was determined using a field emission scanning electron microscope (JEOL JSM-6700F).

\subsection{Experimental design}

In this study, there are several possible control factors for this design. Seven (B-H) of these control factors have three levels, but factor A (substrate) has two. All levels are selected for proprietary reasons according to experience and electrostatic spraying reference information. The substrate materials (A) that were used in the experiments are $\mathrm{Cu}$ and $\mathrm{Al}$, which have high thermal conductance and are commonly used in heat dissipation components. The assignment of the eight factors to an L18 orthogonal array and the subsequent test results are shown. Each trial of the OA had a total of 18 tests and each of the eight factor combinations had two repetitions. The complete list of factors and levels for this experiment is given. The levels for the control factors are the proposed specification limits for the control system design. In the orthogonal array, 18 tests were used to systematically optimize the various control factors with respect to thermal performance and quality..

\section{RESULTS AND DISCUSSION}

\subsection{Surface morphologies}

The surface morphologies of the AlN coatings are shown in Fig. 1. Several parts of the OM images of the surfaces of the coatings obtained in all 18 tests using the orthogonal array table are shown. Clearly, the microscopic hills, voids, valleys and poor surface flatness at the solid-air interface are the greatest barrier to thermal conduction. In terms of the surface roughness values $(\mathrm{Sa})$ of the AlN coatings, as shown in Fig. 1a-1b, sample 14 exhibits the highest value for surface roughness $(4.26 \mathrm{um})$, which corresponds to a $T_{j}$ value of $45.25^{\circ} \mathrm{C}$. This is the worst. Sample $4(1.73 \mathrm{um})$ has the lowest $T_{j}$ value for all of the $\mathrm{L} 18$ tests at $39.7^{\circ} \mathrm{C}$. Figs $1 \mathrm{c}$ $1 \mathrm{~d}$ show that the average volume of the voids on the surface of AlN coatings is measured to be $0.55 \%$ in sample 14 and $0.68 \%$ in sample 4 . The respective volumes of AlN material in both are $6.49 \mathrm{~mm}^{2} / \mathrm{mm}^{2}$ and $3.80 \mathrm{~mm}^{2} / \mathrm{mm}^{2}$, which indicates that sample 4 has a large amount of AIN on the top surface of the films. In other words, the OM patterns confirm that the AlN content for sample 4 is greater than that for sample 14 , so there is a decrease in the contact resistance, which results in a lower thermal resistance. The overall result is confirmed by a lower thermal temperature $\left(T_{j}\right)$, with low surface roughness and a high content of AlN.
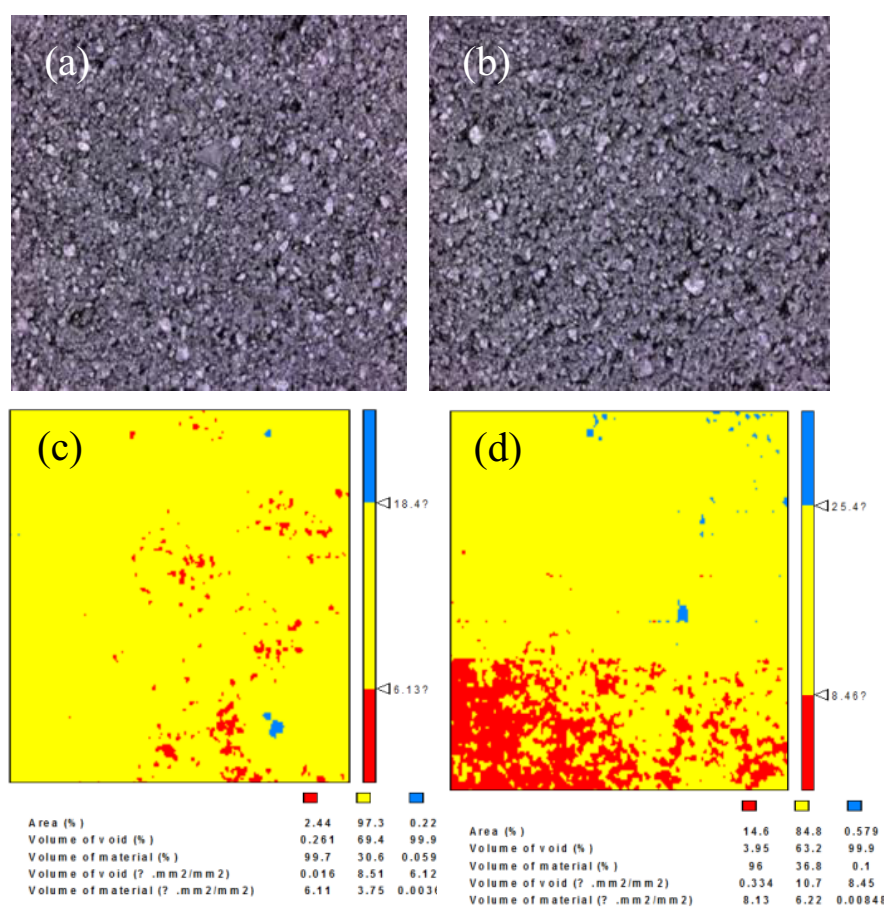

Fig.1. A comparison of the scanning surface morphology and the volume of the voids in the AlN coatings, using a TalyScan 150 instrument for the $4^{\text {th }}$ and $14^{\text {th }}$ tests.

\subsection{Thermal Performance of the AIN Coatings}

In order to test their performance, the AlN coatings were used as a heat sink for a $1.2 \mathrm{~W}$ LED package that was attached to a parallel circuit board. During the thermal test, the LED was driven using a $700 \mathrm{~mA}$ current when it reached a steady state. The observed cooling curves are shown in Fig.2. It is seen that when the driving currents 
are shut down after $60 \mathrm{~min}$, the temperature decreases over time in Figs. $2 \mathrm{a}-2 \mathrm{~b}$ are from $54^{\circ} \mathrm{C}$ to $43^{\circ} \mathrm{C}$ and from $53{ }^{\circ} \mathrm{C}$ to $42{ }^{\circ} \mathrm{C}$, respectively. This shows that the temperature of the LED packages is reduced significantly when an AlN coated Al substrate is driven at $700 \mathrm{~mA}$. Figs. $2 \mathrm{c}-2 \mathrm{~d}$ show the surface curves for temperature $\left(T_{j}\right)$ with a contour. These are plotted to determine the distribution of heat dissipation on an AlN coated $\mathrm{Al}$ substrate. It is seen that the central portion of the $\mathrm{Cu} / \mathrm{Al}$ substrate exhibits the highest $\mathrm{Tj}$ value for $\mathrm{AlN}$ coatings. This may be due to solid-air interface defects in the crystal structure, which increase the thermal barrier and affect the heat conductance.
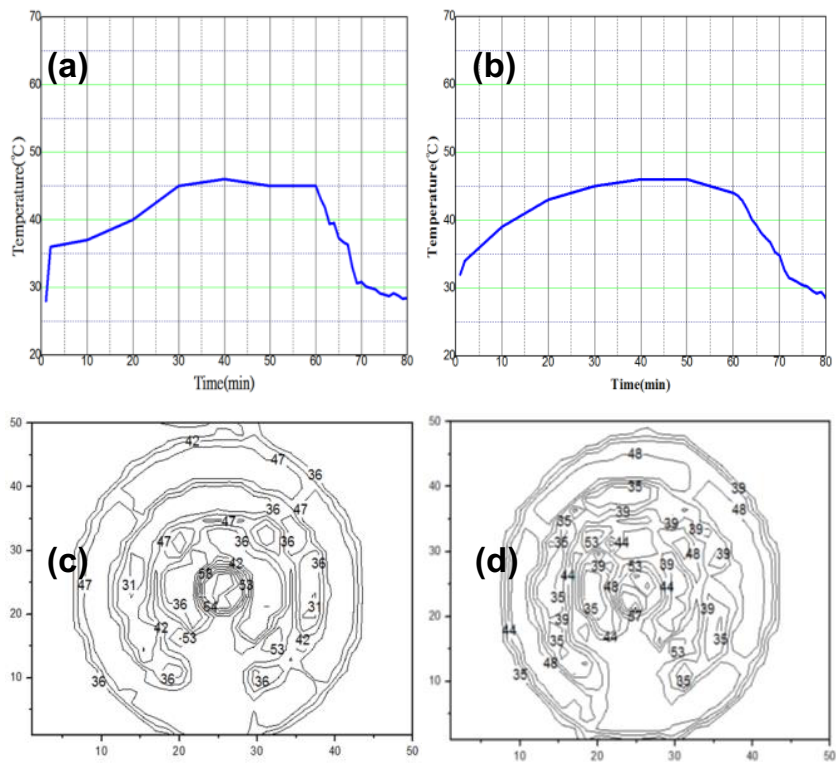

Fig.2. The observed cooling curves for a LED that is driven with a $700 \mathrm{~mA}$ current when it reaches steady state.

\subsection{Thermal resistance analysis}

In this study, the thermal performance of a 1.2W LED on an AlN-coated Al substrate that is used as a heat sink and the influence of the parameters on the $T_{j}$ and thermal resistance $\left(\mathrm{R}_{\mathrm{ja}}\right)$ values are reported. Fig. 3 shows that the $\mathrm{R}_{\mathrm{ja}}$ value for the $\mathrm{Cu}$ substrate is greater than that for the Al substrate. The respective Ave. $R_{j a}$ values are $16.2^{\circ} \mathrm{C}$ $/ \mathrm{w}$ and $15.1^{\circ} \mathrm{C} / \mathrm{w}$. The $\mathrm{R}_{\mathrm{ja}}$ value for the $\mathrm{Cu}$ substrate decreases slightly as the ratio for resin/AlN increases, but the $\mathrm{R}_{\mathrm{ja}}$ value for the $\mathrm{Al}$ substrate decreases significantly, when the ratio of resin/AlN increases. However, the $R_{j a}$ value for the $\mathrm{Cu}$ substrate has the highest value at a resin/AIN ratio of $1: 3\left(17.08 \pm 1.78^{\circ} \mathrm{C}\right.$ $/ \mathrm{w}$ ), but the $\mathrm{R}_{\mathrm{ja}}$ value for the Al substrate has the lowest value for a resin/AIN ratio of $1: 4\left(14.24 \pm 1.54^{\circ} \mathrm{C} / \mathrm{w}\right)$, probably because there is a gradual increase in the concentration of resin particles, which is detrimental to a reduction in the total thermal resistance of the LED packages. The result is inefficient heat dissipation. These results show that the $\mathrm{Cu} / \mathrm{Al}$ samples have better thermal performance with an optimal design for the electro-spraying of AlN coatings.

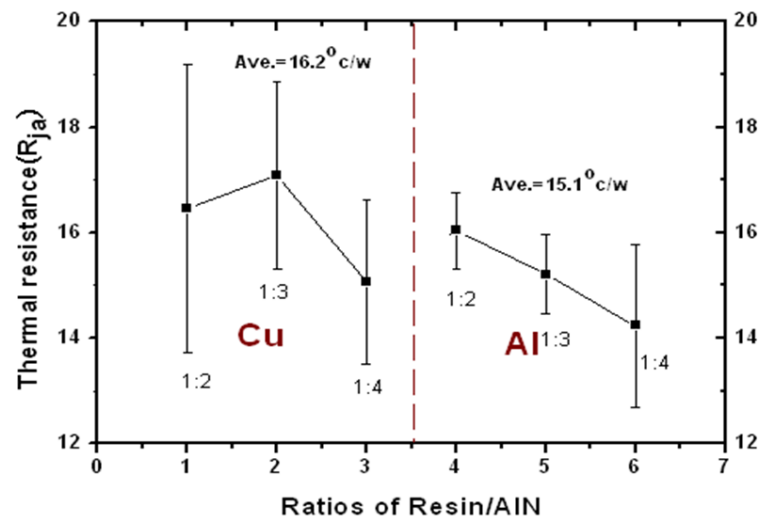

Fig.3. A comparison of the thermal resistance $\left(\mathrm{R}_{\mathrm{ja}}\right)$ for a $1.2 \mathrm{~W}$ LED on AlN-coated $\mathrm{Cu}$ and $\mathrm{Al}$ substrates.

\section{Conclusion}

In this study, the thermal performance of a $1.2 \mathrm{~W}$ LED that uses an electro-sprayed AlN-coated Al substrate as a heat sink and the effect of parameters on the Tj and Rja values are reported. An L18 orthogonal array is used for the LED aluminium/copper plate and the effect of the deposition parameters on the coatings thermal properties is determined. It is observed that the $\mathrm{R}_{\mathrm{ja}}$ value for the $\mathrm{Cu}$ substrate is greater than that for the $\mathrm{Al}$ substrate. The respective Ave. $\mathrm{R}_{\mathrm{ja}}$ values are $16.2^{\circ} \mathrm{C} / \mathrm{w}$ and $15.1{ }^{\circ} \mathrm{C} / \mathrm{w}$. These results demonstrate that the temperature of the LED packages is significantly reduced if there is an $\mathrm{AlN}$-coated $\mathrm{Al}$ substrate and a current of $700 \mathrm{~mA}$. The $\mathrm{Cu} / \mathrm{Al}$ substrate samples with AlN coatings also have better thermal performance when there is an optimal design for the electrostatic spraying process.

This work was financially supported by the National Natural Science Foundation of China (51575110), Natural Science Foundation of Fujian Province (2015J01628), Fujian Provincial Department of Education Research Projects (JA14211) and Fujian Province Industrial Technology Joint Innovation: Research and development of key technology of intelligent rotary die cutting machine (2014).

\section{References}

1. Shanmugan,S.; Mutharasu,D. A.; Haslan, H. International Journal of Electronics and Computer Science Engineering. 2, 1 (2014).

2. Kuo,P. K. G.; Auner,W.; Wu, Z. L. Thin Solid Films. 253 (1994).

3. Lee, J. W.; Cuomo, J. J.; Cho,Y. S.; Keusseyan, R. L. J. Amer. Ceram. Soci. 88, 7 (2005).

4. Huaiyu, Y.; Koh, S. H.; Zeijl, V. A.; Gielen,; W. J.; Guoqi, Z. A review of pas-sive thermal management of LED module. J. Semicon. 32 (2011).

5. Pan, T. S.; Zhang, Y.; Huang, J.; Zeng, B.; Hong, D. H.; Wang, S. L.; Zeng, H. Z.; Gao, M.; Huang, W.; Lin,Y. J. Appl. Phys. 112 (2012). 
6. Heo, Y. J.; Kim ,H. T.; Kim, K. J.; Nahm, S.; Yoon, Y. J.; Kim, J.H. Applied Thermal Engineering. 50 (2013)

7. Lu, X.Y. Hua, T. C.; Wang, Y.P. Microelectronics Journal, 42 (2011)

8. Christensen, A.; Graham, S. Applied Thermal Engineering. 29 (2009).

9. Yung, K.C.; Liem, H.; Choy, H.S.; Lun, W.K. International Communications in Heat and Mass Transfer, 37 (2010).

10. Cheng, T.; Luo, X.B.; Huang, S.; Liu, S. International Journal of Thermal Sciences. 49(2010).

11. Kim,Y.P.; Kim, Y.S.; Ko, S.C.; Microelectronics Reliability. 56 (2016).

12. King, S. Y.; Tseng, J.; Zhao, .J. Applied Thermal Engineering. 52 (2013).

13. Yang, K.S; Chung, C.H.; Tu, C.W.; Wong, C.C.; Yang, T.Y.; Lee. M.T.; Applied Thermal Engineering.70 (2014)

14. Zheng, X.; Ren, Z.; Li, X.; Wang, Y. Applied Surface Science. 259 (2012)

15. Figueroa, U.; Salas, O.; Oseguera, J. Surface and Coatings Technology, 200 (2005)

16. Li, X.; Ren, Z.A.; Sun, D. Q. Materials Science and Engineering A,443 (2007)

17. Rada, N. M.; Triplett, G. E. Solid-State Electronics. 54,4 (2010)

18. Rada, N. Triplett, G. Graham, S. Kovaleski. S. Solid-State Electronics. 52,10 (2008)

19. Zheng, X.; Ren, Z.; Li, X.; Wang. Y. Applied Surface Science. 259,15(2012)

20. Zuo, Z.J.; North, M.T.; Wert, K.L. IEEE Transactions on Components and Packaging Technologies.24,2 (2001)

21. Shinde, S. High Thermal Conductivity Materials, Springer, New York (2006)

22. Shen, W.Q.; Zhu Y.W.; Wang G.L.

23. Appl. Sci. 5 (2015) 